\title{
Alimentando relações e marcando diferenças: Comida brasileira entre imigrantes brasileiros na Grande Boston
}

\author{
VIVIANE KRAIESKI \\ Doutora em Antropologia Social (Universidade Federal de Santa Catarina) \\ Professora na Universidade do Extremo Sul Catarinense \\ Criciúma-Brasil \\ vivianekraieski@gmail.com
}

\begin{abstract}
Resumo Baseado em dados etnográficos, este artigo destaca mudanças e continuidades nas práticas alimentares cotidianas de imigrantes brasileiros na Grande Boston. A alimentação é entendida como parte das estratégias que os sujeitos estabelecem para lidar as dificuldades e os desafios de um novo contexto sociocultural. Argumenta-se que, ao se alimentarem de "comida brasileira", os imigrantes brasileiros estão "alimentando" relações, principalmente as familiares, que têm e mantêm no Brasil. Neste sentido, a "comida brasileira" está associada ao ambiente doméstico e à comida caseira. O artigo também mostra que as mudanças importantes na alimentação dos sujeitos da pesquisa são narradas em relação à rotina alimentar, devido ao horário de trabalho. Destaca ainda a comida como um marcador de identidades e diferenças, servindo como fonte de distinções entre imigrantes brasileiros e norte-americanos, imigrantes de outras nacionalidades, ou até mesmo entre brasileiros, em um complexo contexto intercultural.
\end{abstract}

Palavras-chave: alimentação, imigrantes brasileiros, cotidiano, comida brasileira, mudanças alimentares

\section{Introdução}

"Eu continuo o Brasil na minha cozinha".

\begin{abstract}
A AFIRMAÇÃO ACIMA foi feita por uma interlocutora de uma pesquisa etnográfica que realizei sobre a alimentação de imigrantes brasileiros na Grande Boston, Estado de Massachusetts, nos Estados Unidos. Ela, assim como os outros sujeitos da pesquisa, disse-me que continuava se alimentando de "comida brasileira" após a migração. Estes sujeitos também costumavam narrar as mudanças em termos da rotina alimentar: lá, eles não mais almoçam, apenas jantam. Este artigo destaca estas mudanças e continuidades das práticas alimentares destes indivíduos após a migração, entendendo a alimentação como parte das estratégias cotidianas que os imigrantes estabelecem para lidar com um novo contexto sociocultural, marcado por um complexo sistema interétnico, no qual os brasileiros interagem com norte-americanos e imigrantes de nacionalidades diversas.

Muitos estudos antropológicos já se dedicaram a compreender as práticas alimentares de migrantes nos países para onde migraram. Alguns deles consideram a alimentação como indicador do grau de integração (Lesdain, 2002) ou do estágio de adaptação dos migrantes ao novo contexto (Calvo, 1982), como proteção contra a aculturação e a perda da identidade cultural diante do contato com outros grupos
\end{abstract}


(Contreras e Gracia, 2004), ou ainda como expressão da aprendizagem dos migrantes a um novo modo de vida e da aquisição de novos valores (Jerome, 1980). Estudos mais recentes sugerem entender as (des)continuidades das práticas alimentares como um processo de interpenetração, utilizando como referência a obra de Roger Bastide (1956). Assim, entendem que os imigrantes associam sua cultura de partida com a cultura do país onde vivem, adotando elementos desta outra cultura. De acordo com esta perspectiva, os imigrantes atribuem sentido seguindo as lógicas de seu repertório cultural, mas também de acordo com a estrutura social da sociedade de chegada (Crenn et al., 2010).

A literatura antropológica também aponta que a alimentação pode expressar tanto identidades quanto diferenças culturais que são construídas nas experiências migratórias. Como afirmam Contreras e Gracia, a comida é um elemento através do qual os grupos tomam consciência de sua diferença e etnicidade - entendida pelos autores como um sentimento de fazerem parte de uma entidade cultural distinta - de forma que seu compartilhamento pode significar o reconhecimento e aceitação ou incorporação destas diferenças (Contreras e Gracia, 2004, p. 217). A alimentação é recorrentemente apontada como um dos marcadores de distintividade entre grupos no contexto da migração, visibilizando o processo de construção de fronteiras étnicas (Barth, 1998). Algumas comidas, assim como outros aspectos culturais, são destacados e utilizados como marcadores simbólicos através dos quais os migrantes passam a se identificar (e serem identificados) como grupo étnico (Seyferth, 2005).

Por meio de dados etnográficos, discuto neste artigo as práticas alimentares de meus sujeitos de pesquisa em dois pontos distintos. Primeiro, analiso as continuidades e mudanças da alimentação dos imigrantes brasileiros na Grande Boston. Argumento que, ao se alimentarem de "comida brasileira”, eles estão "alimentando" relações, principalmente as familiares, que têm e mantêm no Brasil. Neste sentido, a "comida brasileira" está associada ao ambiente doméstico, à comida caseira e, muitas vezes, à comida que aprenderam com suas mães. Mostro também que as mudanças na alimentação aparecem principalmente na rotina alimentar devido ao horário de trabalho.

Segundo, a alimentação cotidiana - principalmente no local de trabalho - aparece como um marcador de identidades e diferenças, servindo como fonte de distinções entre imigrantes brasileiros e os outros: norte-americanos, imigrantes de outras nacionalidades, ou até mesmo entre brasileiros de origens distintas. Como afirma Heritier-Augé, "o Outro é, antes de tudo, aquele que come diferente de mim" (1985, p.61). Trabalhando em casas de famílias norte-americanas ou em cozinhas de restaurantes, por exemplo, os brasileiros entram em contato com comidas diferentes, com seus cheiros e sabores, e a partir delas estabelecem relações e constroem conhecimentos sobre os outros.

\section{A heterogeneidade dos brasileiros na Grande Boston}

Os Estados Unidos são o principal destino dos imigrantes brasileiros. Segundo o IBGE, que pesquisou pela primeira vez o número de emigrantes brasileiros no Censo de 2010, há 491.243 mil brasileiros residentes em 193 países do mundo, sendo que, deste total, 23,8\% vivem nos Estados Unidos. Estes números, no entanto, são controversos, já que se trata de um grande contingente de indocumentados. Estudo anterior estimou que, só nos Estados Unidos, haveria entre 800 mil e 1,4 milhão brasileiros, sendo que a maior concentração - 24\%, quecorresponde a 336.000 - estaria no Estado de Massachusetts (Lima, 2009).

No ano de 2009, realizei uma etnografia com imigrantes brasileiros nas towns e cities onde se concentram os imigrantes brasileiros, como Everett, Sommerville, Allston, Malden, Lowell e East Boston. Meu objetivo era compreender as mudanças e continuidades das práticas alimentares de meus sujeitos de pesquisa após a migração, questionando uma afirmação muito recorrente em estudos da área da Antropologia da Alimentação: a fixidez das práticas alimentares, entendidas como um dos aspectos socioculturais mais resistentes às mudanças. Durante o trabalho de campo, convivi com imigrantes brasileiros, realizei entrevistas informais (algumas gravadas, outras não) com pelo menos 20 sujeitos de pesquisa, fui a restaurantes, padarias e mercados brasileiros, acompanhei brasileiros a compras em supermercados norte-americanos, participei de festas e almoços. ${ }^{1}$

Durante minha pesquisa de campo, pude perceber a heterogeneidade dos brasileiros na Grande Boston. Ainda que possa ser verificado um grande número de mineiros, ${ }^{2}$ conheci brasileiros provenientes de diversos estados brasileiros. Eram de diferentes faixas etárias,

1 Durante todo o processo da pesquisa de campo, valorizei a participação (e não a observação) em atividades cotidianas com meus sujeitos de pesquisa, seguindo as orientações de Favret-Saada (2005) sobre a importância da experiência e de "ser afetado" para a construção do conhecimento antropológico (Assunção, 2014).

2 Assis (1995) investigou o grande fluxo de indivíduos de Governador Valadares (Minas Gerais) para a região de Boston. Segundo a autora, há conexões entre os dois lugares desde a década de 1940, quando a extração da mica atraiu estadunidenses para o município mineiro. A circulação do dólar, com cotação superior a da moeda brasileira, no comércio local teria contribuído para a formação da cultura da imigração internacional na região, através da associação, no imaginário popular, entre os Estados Unidos e a riqueza e fartura. 
variando de 22 a 65 anos, e níveis educacionais, desde brasileiros com pouca educação formal até aqueles que concluíram o ensino superior. Tinham também diferentes tempos de permanência nos Estados Unidos e status migratório - brasileiros indocumentados, com visto de estudantes, Green Card (residente permanente legal) e até mesmo com dupla cidadania (brasileira e norte-americana), mas os que lá viviam ilegalmente e que tinham migrado após o ano 2000 eram visivelmente mais numerosos. Estes brasileiros tinham em comum o fato de terem ido para os Estados Unidos a partir do contato e de informações de outros brasileiros, com quem tinham laços de parentesco ou de amizade, o que evidencia que fazem parte de redes sociais (Boyd, 1989, Massey, 1990).

Ainda que tenha encontrado brasileiros com diferentes motivações para migrar, a maioria tinha ido para os Estados Unidos com a intenção de passar um período de tempo (em torno de quatro anos) e retornar para o país após realizarem seu projeto migratório, como a compra da casa própria, montar um negócio ou pagar os estudos dos filhos.

Todos os interlocutores da pesquisa trabalhavam em funções ocupadas por migrantes com pouca ou nenhuma qualificação profissional: serviços de limpeza de casa (como housecleaner e housekeeper), ${ }^{3}$ jardinagem (landscaping), delivery (trabalhos de entrega em domicílio, principalmente de comidas e jornais), trabalhos em cozinhas de restaurantes e construção civil. Os imigrantes provenientes de camadas médias no Brasil experienciavam, nas funções ocupadas nos Estados Unidos, um movimento descendente de status, realizando trabalhos de pouco prestígio social. Como comentou uma de minhas interlocutoras, "aqui não vale o diploma nem o dinheiro", pois, segundo ela, o status social é definido através da situação migratória, já que os maiores privilégios - como a possibilidade de vir ao Brasil e voltar para o país - são daqueles que vivem legalmente nos Estados Unidos.

Ainda que relatem um aumento nos ganhos financeiros nos Estados Unidos, estes imigrantes experienciam muitas dificuldades, especialmente os indocumentados: árdua rotina de trabalho, exploração dos empregadores, ameaças de deportação, pouco ou nenhum conhecimento da língua inglesa, falta de acesso ao sistema de saúde, além da saudade de familiares e amigos que permaneceram no Brasil. A seguir, mostro como a alimentação é uma das formas que os imigrantes utilizam para lidar com essa saudade em seu cotidiano nos Estados Unidos.

\section{Cotidiano e comida brasileira}

Comer e outras práticas que cercam alimentação dos seres humanos, como comprar alimentos e cozinhar, são parte da vida cotidiana. O cotidiano pode ser entendido como a vida de todos os dias, vivida por todas as mulheres e homens em qualquer tempo ou lugar (Heller, 1985, p. 3). É algo construído, que expressa a existência de seres humanos no mundo através da repetição de tarefas e atividades diárias essenciais para sua vivência (Kosik, 1989) - como a alimentação.

Essas tarefas cotidianas, no entanto, podem ser pensadas além de atividades repetitivas. A dimensão do cotidiano, como sugerem alguns autores, é um lugar central de reprodução social. Para Lefebvre (1991), a partir da formação da "sociedade burocrática de consumo dirigido", o cotidiano passa a ser programado por forças sociais e políticas que estão além dos sujeitos que vivem nas cidades. Estas forças teriam o poder, segundo o autor, de planejarem as atividades dos moradores urbanos, tornando-as mais funcionais, semelhante à de uma grande empresa moderna. Este modelo é imposto tendo a racionalidade como valor de organização e melhor funcionamento da sociedade (Lefebvre, 1991).

Já Certeau propõe que o cotidiano também é um terreno potencial de resistência e subversão, e não apenas de complacência e passividade, como sugerem as análises de Lefebvre. $\mathrm{O}$ autor afirma que o cotidiano é formado por tempo e espaço onde se configuram as táticas que os atores sociais desenvolvem para lidarem com as ações engendradas por aparatos dominantes de repressão. Assim como há sistemas que normatizam a vida cotidiana, como pensa Lefebvre, há, para Certeau, espaço para ações de resistência dos sujeitos, através de microações diárias (Certeau, 2009). As obras emblemáticas destes autores sobre o cotidiano nos ajudam a pensar que rotinas podem ser tanto liberadoras quanto constrangedoras. Neste sentido, a pesquisa procurou entender como são feitas as decisões alimentares no dia-a-dia dos imigrantes brasileiros, e como a alimentação é significada e organizada em seus cotidianos.

Os sujeitos de minha pesquisa não tinham grandes dificuldades em encontrar e preparar "comida brasileira" na Grande Boston. O grande número de restaurantes, mercados e padarias, ${ }^{4}$ além da oferta de alimentos brasileiros em supermercados norte-americanos, possibilita o que pode ser compreendido, através dos discursos de meus interlocutores, como uma manutenção das práticas alimentares que tinham no Brasil. Quando perguntados sobre o que comiam em Boston, eram

3 Housecleaner pode ser traduzido como faxineira ou diarista, que realiza eventuais trabalhos de limpeza em casas. Já housekeeper pode ser traduzido como empregada doméstica, que trabalha diariamente em apenas uma casa ou para somente uma família.

4 Não há levantamentos com dados precisos, mas estima-se que haja mais de mil negócios em Massachusetts cujos donos são brasileiros, incluindo pequenos mercados, açougues, padarias, restaurantes, entre outros estabelecimentos (Mendonça, 2007). 
unânimes em responder que era "comida brasileira". A resposta sobre o que é esta "comida brasileira" não é, porém, homogênea, dada a grande heterogeneidade de meus sujeitos de pesquisa, de suas origens (são provenientes de diferentes Estados brasileiros e classes sociais) e trajetórias de vida. A "comida brasileira", portanto, pode compreender tanto o arroz e feijão, consumido por um grande número de brasileiros (Barbosa, 2007), como também macarrão, carnes assadas e ensopadas, e ainda pratos marcados por sua regionalidade, como feijão tropeiro e frango com quiabo.

Esta "comida brasileira" não é preparada exclusivamente com alimentos "brasileiros", ou seja, os alimentos produzidos no Brasil. A maior parte de meus interlocutores afirmou fazer compras em supermercados pertencentes a grandes cadeias norte-americanas. São neles onde compram arroz e feijão, por exemplo. Embora alguns de meus interlocutores consumam arroz brasileiro, a maior parte deles compra com mais frequência o arroz asiático. Segundo me explicaram, este é o mais consumido por ser "branco e soltinho", semelhante ao brasileiro. Outro fator que leva ao consumo deste arroz é o preço inferior ao produto brasileiro. Já o feijão mais consumido é o da marca Goya (marca de alimentos rotulados como latinos ou hispanos) que apresenta diversas variedades. Sonia, ${ }^{5}$ por exemplo, disse-me comprar feijão Goya "que é igual ao carioquinha", e outros interlocutores, como Andréa, compram o "feijão vermelho", da mesma marca. A comida brasileira, preparada pelos imigrantes brasileiros na Grande Boston, assemelha-se aos "objetos compostos", descritos por Ortiz (1994) como uma das características da mundialização da cultura, na qual os objetos são resultados de uma combinação de diferentes partes produzidas de forma dispersa pelo planeta.

Diferentemente do arroz e do feijão, raros produtos, como o café, são comprados de marcas brasileiras. O café brasileiro Pilão é bastante consumido entre os interlocutores de minha pesquisa. No entanto, encontrei muitos brasileiros que consomem o café colombiano da marca Bustelo, que dizem ser "igual ao brasileiro". Assim como o arroz asiático, este café também costuma ser vendido a preços menores que o café brasileiro, e pode ser comprado em alguns mercados brasileiros da região.

Se a maior parte das compras é feita em supermercados norte-americanos, nos mercados brasileiros são feitos os "picadinhos", para utilizar uma expressão comum entre meus interlocutores. Nestes mercados, são comprados produtos que geralmente não são encontrados nos supermercados, como azeite de dendê, queijo mineiro, requeijão, doces mineiros em compotas, doce de leite, além de uma maior variedade de biscoitos e bolachas.

A carne é talvez o alimento mais controverso entre meus interlocutores. Há uma unanimidade entre eles em afirmar que a carne brasileira é mais saborosa, ou "tem mais gosto", usando uma expressão recorrente entre os brasileiros. Muitos deles disseram-me comprar carnes apenas em açougues brasileiros, por causa da diferença de corte entre os açougues brasileiros e norte-americanos. Alguns interlocutores, inclusive donos de restaurantes, explicaram-me que a carne vendida em Massachusetts é proveniente de outros estados norte-americanos, principalmente do meio-oeste do país, ou ainda de outros países como a Austrália. Uma das explicações para a "falta de sabor" seria o congelamento da carne e a embalagem a vácuo, para facilitar o transporte. As carnes vendidas tanto nos açougues brasileiros quando nos supermercados e açougues norte-americanos apresentam, desta forma, a mesma origem, e apenas se diferenciam pelo corte.

Além destas diferenças de corte, há uma dificuldade, principalmente entre os que não dominam o inglês, em compreender os nomes dados aos cortes de carne vendidos em supermercados ou açougues norte-americanos. Alguns brasileiros, como João, que fora açougueiro no Brasil e não tem muito conhecimento de inglês, afirmaram reconhecer os cortes devido a esta experiência prévia em açougues. Estes brasileiros que dominam o inglês ou que tem um conhecimento sobre cortes de carne geralmente compram carne em supermercados e açougues norte-americanos, onde o preço é geralmente menor.

A maioria dos produtos comprados que servem como ingredientes para o preparo da "comida brasileira”, portanto, não são provenientes do Brasil. A relação estreita entre comida, identidade e território já fez autores afirmarem que a comida é um elementos de uma cultura mais resistente a transformações e, por esta razão, um dos últimos a se desnacionalizar (Cascudo, 2003). Essas afirmações, no entanto, podem mascarar a mobilidade da comida, atrelando-a a um território fixo. Como aponta Gibson, o que é considerada uma comida inglesa é, na verdade, resultado de mobilidades complexas e contraditórias. Podemos estender esta afirmação à culinária brasileira, ou culinária praticada por brasileiros, pois as cozinhas não são limitadas por geografia ou nacionalidade (James, 2003). Cada cozinha tem traços de mercado, viagens e tecnologia (Mennell, 1985, Mintz,1985). Cook e Craig (apud Gibson, 2007), apontam que as comidas não são apenas artefatos culturais localizados, mas também deslocalizados (dis-placed). Gibson esclarece que este deslocamento não é um fenômeno recente, pois, como um objeto da cultura, sempre houve um movimento da comida do local onde foi produzida até chegar ao prato dos indivíduos (Gibson, 2007, p. 14).

Ortiz também considera que processos de mundialização e a modernidade rompem as relações entre lugar e alimento. "Os alimentos descolam de suas territorialidades para serem distribuídos em escala mundial" 
(Ortiz, 1994, p. 80). A mundialização não se sustenta apenas por avanços tecnológicos, mas também por objetos compartilhados em grande escala que acabam por constituir nossa paisagem. "As corporações transnacionais, com seus produtos mundializados e suas marcas facilmente identificáveis, balizam o espaço mundial" (Ortiz, 1994, p. 107). Deste modo, compreende-se que "comida brasileira" seja também preparada com alguns produtos que podem ser facilmente encontrados nos Estados Unidos por serem de marcas que já faziam parte do repertório de compras dos brasileiros antes do processo migratórios.

A "comida brasileira" é preparada, em sua maior parte, com ingredientes de "gosto" mais parecido ao do Brasil. Quando um produto não-brasileiro é comprado, recorrentemente é comparado ao brasileiro, e classificado como "igual ao do Brasil". Nesta substituição de produtos, há um papel fundamental das interações entre as redes sociais. Através do contato destas redes, há uma troca de experiências entre os imigrantes, que recomendam ou não a compra de determinados alimentos de marcas específicas, e contribuem para que estes produtos façam parte do repertório de compra de outros sujeitos.

Não sendo feita exclusivamente com produtos brasileiros, a "comida brasileira" é geralmente associada à comida feita em casa, em oposição à comida pronta de restaurantes fastfood, que são descritos pelos sujeitos de pesquisa como norte-americanos. Embora nem toda cadeia de fastfood tenha se originado nos Estados Unidos, é muito comum entre os imigrantes brasileiros a descrição da comida norte americana como a preparada e servida em cadeias como McDonald's e Burger King. ${ }^{6}$ Neste sentido, é interessante a afirmação de Elias, que explica que a comida que prepara em sua casa "é bem brasileira": "lá em casa é comida de panela. Lá em casa não tem hamburger, Burger King, Mcdonalds, nada disso."

Esta comida caseira também é oposta à comida industrializada, como o feijão enlatado. Desta forma, a "comida brasileira" é a comida preparada em casa, para a família, como explica Mônica:

Eu continuo o Brasil na minha cozinha. Nada muda. Às vezes nem feijão em lata eu gosto de comprar. Eu cozinho. Minha filha diz: mamãe, para. Mas eu não consigo. Final de semana ainda sai da rotina. Mas final de semana é normal. É café da manhã, almoço, quando chego do serviço ainda tem a janta.

O feijão enlatado foi citado por alguns interlocutores como um de seus itens eventuais de compra. Mas, para ser consumido, este feijão era "abrasileirado" - ou seja, adicionavam-se temperos considerados "brasileiros", como alho, cebola e outros condimentos. Desta maneira, este produto preparado de forma industrial ganhava "gosto" caseiro, assim como a comida preparada em casa.

Sugiro que "comida brasileira" está mais associada à domesticidade e à comida caseira, do que propriamente a noções de nacionalidade. Quando declaram que não mudaram suas práticas alimentares e que continuam se alimentando de "comida brasileira", mais do que afirmarem uma identidade brasileira, estes brasileiros estão procurando estabelecer e reforçar as relações mais significantes que têm com aqueles que permaneceram no Brasil. A comida caseira destes imigrantes é, segundo a maior parte de meus interlocutores, a comida que aprenderam a fazer com suas mães. Como declarou uma de minhas interlocutoras em Boston, que tinha a mãe no Brasil, "o nosso país é onde a nossa mãe está”.

Como afirma Codesal, a migração é também uma experiência corporal. Os imigrantes deixam para trás um ambiente sensorial, com cheiros e sabores. Por esta razão, a comida pode ser usada para compensar o sentimento de descontinuidade ou fragmentação que a migração traz às vidas das pessoas (Codesal, 2010). Podemos ainda enfatizar que os imigrantes não procuram consumir apenas alimento, mas comida, tal como diferencia DaMatta. O alimento, segundo o autor, é algo universal e geral, ou nas palavras de DaMatta, "tudo aquilo que pode ser ingerido para manter uma pessoa viva". Já a comida é marcada pelo prazer e comensalidade, e "ajuda a estabelecer uma identidade, definindo, por isso mesmo, um grupo, classe ou pessoa" (DaMatta, 1987). Seguindo esta concepção, podemos pensar também a comida caseira a partir da perspectiva de DaMatta sobre a casa (em contraposição com a rua). A casa seria o lugar do reconhecimento, da hospitalidade, da recuperação, do repouso, ou ainda, como coloca o autor, "de tudo aquilo que define a nossa ideia de 'amor', 'carinho' e 'calor humano”. A casa, ao contrário da rua, que é o lugar da impessoalidade e da ausência de vínculos, é marcada pelos laços de parentesco e de afinidade (DaMatta, 1997). Assim, a comida caseira está associada ao conforto do lar e dos vínculos familiares.

A literatura antropológica enfatiza com recorrência as relações entre comida e parentesco. Woortmann (1986), por exemplo, afirma que as refeições das famílias camponesas não são apenas um ato de comer, mas também um ato ritual que reproduz simbolicamente a hierarquia da família. Desde modo, através das refeições, as famílias alimentam não apenas seus corpos biológicos, mas também suas representações. $\mathrm{Na}$ etnologia indígena, as relações entre comida e parentesco também 
são evidenciadas. Vilaça (2007) retrata, em seu estudo sobre os Wari', que o parentesco e as relações são constantemente produzidos por atos da vida diária, como o comer. Partilhar a comida, entre outras práticas cotidianas, implica constituição de corpos semelhantes, o que caracteriza o parentesco consanguíneo. Neste sentido, as ações produzem os parentes, e não o inverso, como nas sociedades euro-americanas. Inspirando-nos nestas análises, podemos pensar que, ainda que não produza o parentesco, a comida consumida por migrantes em Boston reafirma vínculos sociais, especialmente os de parentesco, sendo utilizados para diminuir a distância geográfica que separam brasileiros nos Estados Unidos e no Brasil.

Esta comida "brasileira" pode ser entendida ainda em analogia com o movimento de mundialização analisado por Ortiz. Segundo o autor, este movimento percorre dois caminhos: primeiro da desterritorialização, que constitui um espaço abstrato e deslocalizado. Para existir, este espaço deve se "localizar", preenchendo este vazio de sua abstração com "objetos mundializados". Deste modo, o mundo passa a ser reconhecível (Ortiz, 1994). De maneira semelhante, os imigrantes se desterritorializam, levando consigo seus hábitos e valores. Para se "localizarem", adotam práticas transnacionais, produzindo sua comida a partir de produtos não-brasileiros. Assim, procuram recriar um ambiente sensorial familiar e lidar com as dificuldades da distância da terra natal e de seus vínculos sociais, e da nova e árdua rotina de trabalho.

\section{"O lunch é lanche": as mudanças na rotina alimentar}

Com grande recorrência, os interlocutores da pesquisa narravam a mudança em sua alimentação diária em relação a suas rotinas alimentares: no Brasil, almoçavam; agora, nos Estados Unidos, jantam. Frequentemente falavam que antes de migrarem tinham tempo para comer, o que não ocorre nos Estados Unidos.

Estas afirmações levam à reflexão sobre o que é considerado "almoço" para meus sujeitos de pesquisa. Em geral, o almoço é caracterizado pela comida, que seria arroz, feijão, macarrão, carne e saladas, sem que todos estes ingredientes tenham que estar necessariamente presentes, mas que devem ser consumidos quentes (refiro-me à temperatura). Neste sentido, é bastante ilustrativa a afirmação de meus interlocutores de que os norte-americanos não costumam almoçar: "o lunch deles é lanche", explicando, deste modo, que comer um sanduíche não é sinônimo de almoço. Já Sonia afirmou que "americano come qualquer coisa" no almoço:"Eles comem pão com peanutbutter, mas eu gosto é de arroz".

Já que não almoçam, a principal refeição do dia de meus interlocutores é a janta. Isto se deve princi- palmente à rotina de trabalho. Conheci um grupo de housecleaners que afirmou que, em suas rotinas diárias de limpezas de diversas casas, não tinham "tempo para comer". Quando conversei pela primeira vez com Rosa, ela me contou que tinha passado o dia - das dez horas da manhã às cinco e meia da tarde - bebendo apenas água. Depois desta rotina, disse-me chegar em casa cansada com muita fome - assim, não tem vontade de cozinhar e "come tudo".

Observei que a mudança na rotina alimentar de meus interlocutores é narrada em relação ao tempo ou à falta dele, marcado pelo trabalho. $\mathrm{O}$ tempo não é algo natural, mas produto de um processo social, como indicam Lefebvre e Regulier (1985). Estes autores consideram que a vida cotidiana se organiza sobre o tempo abstrato e quantitativo dos relógios. A vida cotidiana seria o resultado de uma interação de grandes ritmos cósmicos - como os dias e as noites, as estações do ano e ainda os ritmos biológicos - e os processos repetitivos relacionados ao tempo homogêneo (Lefebvre e Regulier, 1985). Este tempo - introduzido pouco a pouco no Ocidente após a invenção dos relógios - fornece a medida do tempo do trabalho, e passou a ser o tempo da cotidianidade. Lefebvre e Regulier salientam que este tempo cotidiano subordina à organização do trabalho no espaço de outros aspectos do cotidiano, como as horas de dormir e de acordar, o lazer, as relações dos adultos com as crianças, assim como as horas das refeições.

Há uma luta entre o tempo e o emprego do tempo. Assim como o espaço, o tempo se divide em parcelas, como trabalhos, distração, lazer. Não há, nas palavras dos autores, um tempo para todo fazer, mas cada fazer tem seu tempo. Estes fragmentos são hierarquizados, ficando o trabalho com uma grande parcela (Lefebvre e Regulier 1985, p. 192). Outros comportamentos, aparentemente espontâneos, são adquiridos através da repetição constante, em tempos regulares, que chega a organizar até mesmo o que está estreitamente relacionado ao biológico e fisiológico, como a fome (Lefebvre e Regulier, 1985, p. 191).

Alguns brasileiros disseram-me preparar marmitas - levar comida pronta, geralmente preparada na noite anterior, para comer no horário do almoço (por volta de meio-dia) durante o trabalho. João, por exemplo, tinha um aparelho microondas dentro do carro para aquecer as marmitas no horário do almoço. Outras pessoas, porém, têm dificuldades em aquecer a comida. Pelo menos duas housecleaners contaram-me que não aqueciam comida nas casas de patroas norte-americanas porque a comida brasileira "dava cheiro". Como aponta Hondagneu-Sotelo (2007) a respeito de domésticas latinas na Califórnia, a comida e as refeições simbolizam uma fronteira social entre as trabalhadoras imigrantes e as famílias para quem trabalham. A autora refere-se principalmente ao fato de muitas housekeepers não comerem junto com estas famílias no momento das refeições, pois o comer junto estaria relacionado a ser 
membro de uma família. ${ }^{7}$ Neste caso de algumas housecleaners, a comida continua estabelecendo esta fronteira, através de seu odor, que impedem as trabalhadoras de se alimentarem na casa dos patrões. O odor poderia ainda transpassar os limites das casas dos patrões - a rejeição da comida das empregadas, portanto, estabelece uma fronteira simbólica também com a vizinhança daqueles para quem trabalham.

Por outro lado, em alguns casos, são as housecleaners que se recusam a comer na casa dos patrões. Rosane contou-me que "tinha nojo" em se alimentar na casa de norte-americanos, por causa da sujeira. Observação similar foi realizada pela antropóloga Soraya Fleischer (2000), em pesquisa com housecleaners brasileiras na Grande Boston. Fleischer afirma que suas interlocutoras descrevem os norte-americanos como "sujo", "porco", "pouco caprichoso", "mal cheiroso", inclusive em relação à alimentação. Deste modo, noções de limpeza são utilizadas para marcar alteridade (Fleischer, 2000).

Além do horário de trabalho, outro fator que contribui para que a janta seja a principal refeição em família é o horário de funcionamento das escolas norte-americanas onde estudam os filhos dos imigrantes brasileiros. A maioria das aulas começa pela manhã, e os alunos são liberados apenas no meio da tarde, por volta das três horas. Durante este período, toda a alimentação é feita dentro do colégio. Geralmente, são vendidos lanches nas escolas, como sanduíches e pizzas. É possível também que os alunos levem marmita ou lanche de casa, porém estes nem sempre podem ser aquecidos. Lúcia, que trabalhava na mesma escola em que a filha estuda, falou-me que esquentava a marmita que levava para a filha comer durante o almoço, e enfrentava o estranhamento dos professores e funcionários da escola.

A alimentação de adolescentes filhos de imigrantes brasileiros é motivo de conflitos em diversas famílias. Com a circulação destes jovens em espaços onde se concentram indivíduos norte-americanos e de outras nacionalidades, como as escolas, eles entram em contato com práticas alimentares que se desviam daquilo que é considerado saudável e correto por seus pais e familiares, como pizzas, hamburgers e outras comidas de fastfood. ${ }^{8}$ Estas comidas estão associadas não apenas a práticas culturais do contexto em que os imigrantes vivem (e que não se restringem apenas a ele, pois podem ser encontrados nas cidades brasileiras), como também à sociabilidade destes jovens, que buscam se inserir na sociedade norte-americana. Esta inserção ocorre, muitas vezes, em conflito com as práticas culturais e sociais dos pais, como as práticas alimentares, de quem tentam se diferenciar. ${ }^{9}$

O jantar é feito principalmente em casa, na presença de todos os membros das famílias, quando os imigrantes vivem com os familiares nos Estados Unidos. No entanto, alguns de meus sujeitos de pesquisa contaram-me que, em suas rotinas, é comum cada membro da família jantar em um horário diferente, devido às diferentes rotinas de trabalho.

Nestes casos, um dos membros - geralmente as mães, mas também os pais e as avós - preparam o jantar, e cada um aquece o jantar no momento em que chega em casa. Concordo com Murcott (1997) de que as refeições em família não podem ser generalizadas como coisas do passado. Embora não almocem, os interlocutores de minha pesquisa procuravam estabelecer horários para a janta de forma que todos os integrantes da família estivessem presentes. Quando isto não era possível, ainda assim a janta era feita em casa, cada familiar comia em horário diferente em função de seu trabalho, mas a comida continuava sendo preparada por um membro da família - a maioria, mulheres e/ou mães. Assim, como Haukanes (2007) aponta, não se deve buscar apenas o que separa as famílias, mas aquilo que constitui sua relação na vida diária, os processos pelos quais as pessoas constroem relações. A autora mostra que, entre seus entrevistados na República Tcheca, comer em família durante a semana não parecia ser uma preocupação. A preparação da comida, ao contrário, era muito importante na rotina diária de mulheres, que era aceita como uma responsabilidade autoevidente. Desta forma, a comida preparada em casa, e não apenas o comer junto, fornece um meio para criar proximidade social e fortalecer os laços familiares e de parentesco. ${ }^{10}$

Estas refeições em casa estão geralmente associadas às famílias e com menos recorrência às pessoas que vivem sozinhas ou dividem a casa com roomates sem grau de parentesco. Alguns homens atualmente casados disseram-me que, quando chegaram a Boston, solteiros, enfrentaram dificuldades por não saberem cozinhar. Alguns deles aprendem a cozinhar nos Estados Unidos.

7 De forma semelhante, Douglas e Isherwood expõem esta importância dos bens - o que inclui a comida - na interação entre os sujeitos:

"Ao serem oferecidos, aceitos ou rejeitados, eles reforçam ou solapam as fronteiras existentes" (Douglas e Isherwoord, 2006, p. 120).

8 Contreras afirma que o hábito alimentar de junk-food dos adolescentes norte-americanos, baseado em hambúrguer, pizza, batata-frita e refrigerante, deve ser considerada dentro do contexto de uma experiência social que inclui música, ruído e companhia. (Contreras, 1992, p.11) 9 Como mostra Garabuau-Moussaoui (2001), em pesquisa realizada com jovens franceses, esta alimentação considerada desequilibrada e desregrada tem a função social de participar da construção de uma identidade geracional temporária, em ruptura com a identidade dos pais dos jovens. 10 De forma semelhante, Viegas (2007) mostra que a comida tem papel importante na produção do parentesco entre os Tupinambás. Segundo ela, a comensalidade não é importante, pois os momentos em que as pessoas se reúnem para uma refeição são raros, mas o compartilhamento de alimentos cozidos no mesmo fogo. 
A maioria dos recém-chegados, no entanto, tem em comum a experiência de comer com mais frequência em redes de fastfoods. Neste sentido, os fastfoods desempenham entre os imigrantes recém-chegados o mesmo papel apontado por Rial em relação aos turistas de diferentes nacionalidades. Segundo a autora, os fastfoods são bastante frequentados por estes por representarem uma sensação de familiaridade, por seus clientes saberem com antecedência o que podem esperar da cozinha. Nas palavras de Rial, estes espaços "são lugares, portanto, percebidos como ilhas de território conhecido em meio ao desconhecido, pontos de referência na trajetória itinerante criado pelo turismo em seu movimento de circulação" (Rial, 1997, p. 156). Mas, além desta familiaridade, há também um fator econômico: durante minha estadia em Boston, houve promoções em algumas cadeias que vendiam hamburgers a um dólar.

De modo geral, esta experiência de comer fora está geralmente relacionada na literatura antropológica a um fator de distinção entre classes sociais, pois seria um sinal de refinamento e acúmulo de capital cultural (por exemplo, ver Warde e Martens 2000). No entanto, minha experiência com brasileiros em Boston mostrou que o comer em casa estava relacionado a um estabelecimento na e a um conhecimento da cidade. Para preparar a comida, é preciso saber onde comprar os alimentos, ter um conhecimento sobre os produtos que são vendidos nos supermercados norte-americanos, um saber-fazer das substituições de produtos brasileiros por outros encontrados por lá. Neste sentido, passar a comer em casa demonstra um capital acumulado através das experiências de circulação na cidade e de informações que circulam nas redes sociais.

A distinção entre classes sociais, porém, não pode ser descartada da experiência de comer fora. Comer em restaurantes norte-americanos, ou ainda restaurantes étnicos não-brasileiros, pode ser relacionado à posse de capital cultural, pois esta prática é geralmente feita por brasileiros que têm domínio de inglês, são provenientes de camadas médias no Brasil ou migraram para os Estados Unidos há pelo menos uma década e experienciaram ascensão social. Neste sentido, concordo com Warde et al (1999, p. 124) que "a experiência das cozinhas estrangeiras é uma marca de refinamento, a posse dessa experiência está relacionada com a classe social". Segundo Warde et al, essas habilidades têm que ser adquiridas através da exposição a restaurantes e informações sobre "bom gosto" e "bom tom".

Conhecer e apreciar diferentes culinárias pode fornecer aos sujeitos uma maior mobilidade entre restaurantes e culturas culinárias. A mobilidade, segundo Bauman (1999), indica uma nova polarização moderna (ou pós-moderna) das condições sociais que separam indivíduos na hierarquia social. $\mathrm{O}$ autor considera que a mobilidade é o valor mais cobiçado, sendo que a liberdade de movimentos torna-se "uma mercadoria sempre escassa e distribuída de forma desigual" (Bauman,
1999, p. 08). Neste sentido, Bauman considera que a elite se torna cada vez mais global, enquanto o restante da população está mais localizada. É neste sentido que Bauman expõe dois processos da globalização estreitamente relacionados que diferenciam as condições de vida dos sujeitos. Juntamente com os fluxos planetários - de negócios, finanças, comércio e fluxo de informação - há um processo 'localizador', de fixação no espaço (Bauman, 1999, p. 08).

O acúmulo deste tipo de capital cultural também pode ser associado à experiência de trabalho. Muitos brasileiros trabalham como garçons e em diversas ocupações nas cozinhas de restaurantes na Grande Boston. Esta experiência fornece um conhecimento de diferentes culinárias, como me contou Elias, e estabelece formas de distinção com brasileiros que não possuem este capital:

\begin{abstract}
"É incrível quando eu vou aos restaurantes, que eu tenho que pedir a comida pras pessoas, porque as pessoas não conhecem. O que quer dizer isso? Quem não trabalhou em restaurante, não conhece e tal. (...) Como eu tenho um vasto conhecimento em restaurante, aí você come uma comida do leste europeu, uma comida francesa, uma comida americana mesmo... então é específico os lugares que você vai pra comer... Mas o brasileiro em geral, o mundo dele é esse. Ele não quer sair do arroz e feijão".
\end{abstract}

Deste modo, o mapeamento dos restaurantes e dos melhores momentos para frequentá-los é mais um conhecimento que se agrega ao capital cultural dos trabalhadores de restaurantes, e pode servir como elemento de e para distinção (Bourdieu, 1979) entre os imigrantes.

Os brasileiros que trabalharam ou ainda trabalham em restaurantes, fastfoods e outros estabelecimentos que vendem comidas, como pizzarias, contaram-me que fazem as refeições enquanto estão trabalhando nestes locais. Em geral, estes trabalhadores comem a comida que é preparada e/ou vendida lá. Além da possibilidade de comerem em intervalos curtos da jornada de trabalho, o fato de poderem se alimentar sem nenhum custo adicional é apontado como uma vantagem de se alimentar nestes estabelecimentos. Maria, por exemplo, vive nos Estados Unidos há pelo menos vinte anos, e trabalhou em diferentes restaurantes. Assim que chegou, trabalhou em um restaurante de comida árabe, de proprietários libaneses. Depois, foi garçonete de um restaurante italiano. Nestes dois trabalhos, costumava comer no trabalho. A estranheza inicial em comer uma comida desconhecida, como os salgados árabes, é compensada pelo acompanhamento de seu preparo: conhecendo os ingredientes e o modo como é feita estimula experimentar uma comida nova, e torná-la parte de seu repertório de consumo. $\mathrm{O}$ trabalho em restaurantes também familiariza homens como a atividade de cozinhar, o que pode levar a mudanças na divisão de tarefas por gênero nas famílias. 
Este comer em restaurantes em intervalos do trabalho não é, porém, apontado com recorrência como uma refeição. Desta forma, come-se nestes locais de trabalhos, mas não se almoça, ou janta, o que parece relacionar as refeições de almoço e jantar às práticas alimentares realizadas em casa, com comidas, em maior parte, caseiras, e, em muitos casos, com a presença de outros membros da família

Entre meus interlocutores, era recorrente comer em restaurantes brasileiros nos finais de semana, especialmente aos domingos. Na maioria destes restaurantes, é servido o "espeto corrido", com churrasco - nestes casos, os clientes pagam uma quantia para servirem-se à vontade do buffet (geralmente contendo arroz, feijão, feijão tropeiro, farofa e saladas) e ainda são servidos com carne assada em espetos nas mesas. $\mathrm{O}$ almoço de domingo, portanto, caracteriza-se por ser a refeição em que se come mais e melhor, recorrentemente apresenta carne assada, e é feita em família, conforme apontam diversos estudos antropológicos (ver Woortmann, 1986).

Enquanto a maior parte de meus interlocutores afirma que sua alimentação não sofreu mudanças após a migração para a região de Boston, algumas mudanças, além da rotina alimentar, podem ser percebidas em suas práticas alimentares. Neste sentido, é importante atentar para as diferenças ou incoerências que constituem a relação entre discursos e práticas. Um dado interessante é que a maior parte das adoções de "alimentos americanos" são mais comuns nos cafés da manhã. Desta forma, brasileiros mostraram-se bastante familiarizados com produtos como peanutbutter e outros cremes vendidos em supermercados norte-americanos. Na casa de Monica, que tem duas filhas casadas com norte-americanos, é comum tomar breakfast nos sábados. A comida é pedida em um fastfood onde a filha trabalha. Segundo me contou, algumas vezes, a refeição é feita naquele local e, em outras, a comida é levada para casa. O pedido é individualizado: cada membro da família escolhe o que quer comer.

“A gente não muda [a alimentação]. No sábado sim, a gente sai para tomar o café, o breakfast a gente faz fora.A gente come sim, mas é panqueca, essas coisas assim. Mas não é rotina. (...) Você escolhe lá no menu e cada um pede uma coisa. A gente começa o breakfast umas dez e meia, onze horas".

Esta adoção do breakfast - nota-se que a palavra em inglês é utilizada na fala de minha interlocutora, marcando diferenças que também estão relacionadas aos alimentos que estão ingeridos - pode ser entendida dentro de uma hierarquia das refeições. Alguns estudos mostram que o café da manhã é percebido como uma refeição simbolicamente inferior se comparada a outras, como o almoço e, principalmente, no caso de meus interlocutores, o jantar (Douglas,1971). Deste modo, por ser menos significativa simbolicamente, esta refeição estaria mais sujeita a alterações e mudanças. No caso de Monica e também de outros interlocutores, esta refeição nos sábados ou ainda em dias de folga ("dias de off', conforme expressão utilizada pelos brasileiros) recorrentemente é feita onde um dos membros da família trabalha. Tomar café nestes lugares é um modo de transformar um local de trabalho em um local de consumo da família.

Mudanças alimentares também são feitas em relação ao tipo de trabalho que os imigrantes passam a desempenhar. Dois interlocutores disseram-me ter voltado a comer carne vermelha depois que migraram para os Estados Unidos, após anos de vegetarianismo ou da ausência de carne vermelha em sua alimentação. Esta mudança deveu-se às qualidades simbólicas associadas à carne - como força e resistência fisica - que deveriam ser apropriadas por estes sujeitos através do consumo, para auxiliá-los na jornada de trabalho que requeriam grande resistência fisica. ${ }^{11}$ Graça, por exemplo, contou-me voltou a comer carne, relacionando a rotina árdua de trabalho a uma degradação da alimentação e à adoção de práticas que contrariam valores relacionados à alimentação correta e saudável.

\section{O que os outros comem}

Em meu trabalho de campo, estive em contato com diversas mulheres brasileiras que trabalhavam como housecleaners e housekeepers. Concordo com Ribeiro (1998) de que pesquisas com estas empregadas domésticas podem constituir uma importante via de leitura para compreender diferenças culturais entre brasileiros e norte-americanos, pois se trata de um trabalho que implica "uma imersão no mundo privado". Durante suas longas de rotinas de trabalho, a maior parte realizada em casas de famílias norte-americanas, muitas delas bastante abastadas, estas mulheres confrontam-se com diferenças no modo de vida, como as relações de gênero entre mulheres e homens, e outras, como as práticas alimentares. É comum, portanto, que estas mulheres apresentem-se como conhecedoras do que comem e do que preferem comer os norte-americanos.

Percebe-se que o modo como descrevem estas diferenças está bastante relacionado a estereótipos mais generalizantes que tratam de modo depreciativo os grupos da sociedade hospedeira e outros grupos migrantes. Esta mesma descrição, em contrapartida, ressalta os aspectos positivos que os imigrantes destacam para

110 consumo de carne, principalmente o de carne vermelha, também é bastante associado à masculinidade. Deste modo, acredita-se que os homens precisem comer carne vermelha, como apontam Bourdieu (1979), Fiddes (1991) e Barthes (1985). 
descreverem a si mesmos, valorizando-se e distanciando-se dos demais grupos.

Como mostra Roberto Cardoso de Oliveira (1976), a afirmação de um indivíduo ou grupo ocorre através da diferenciação em relação a outros indivíduos ou grupos com que se defronta. Neste sentido, a identidade étnica é contrastiva, ocorre por oposição e não se afirma isoladamente, pois "nega" a(s) outra(s) identidade(s). A identidade étnica, ainda segundo o autor, é contextual e engendrada através do contato interétnico. Este processo de identificação é marcado pelo etnocentrismo, que Cardoso de Oliveira define como uma incapacidade universal da ideologia étnica de se relativizar, valendo-se apenas de critérios absolutos (1976, p. 47). Assim, os contrastes que definem estas identidades ocorrem por meio de discriminações e generalizações dos "outros" (Oliveira, 1976).

Deste modo, os norte-americanos, frequentemente caracterizados pelos brasileiros como preguiçosos e que "não querem trabalhar", são descritos como indivíduos que não cozinham e que só se alimentam de "comida pronta" e fastfood. A housekeeper Karen foi uma de minhas interlocutoras que afirmou que "os americanos não cozinham", e que os filhos de seus patrões "só comem besteira", como batata frita. ${ }^{12}$ Hondagneu-Sotelo (2007) mostra que a comida, entre housekeepers latinas, captura a essência de como as trabalhadoras imigrantes se sentem a respeito de seus trabalhos e a relação que estabelecem com as famílias de seus patrões. Deste modo, a comida pode estabelecer tanto fronteiras de exclusão como de inclusão, marcando o grau em que as famílias reconhecem as imigrantes como seres humanos que têm necessidades humanas básicas.

Fleischer afirma que as housecleaners brasileiras em Boston diferenciam seu trabalho daquele feito por $b a$ by-sitters, e percebem que os empregadores norte-americanos são mais exigentes na escolha destas babás. Estes preferem as migrantes europeias brancas e exigem mais habilidade e experiência, além de cadastramento em agências especializadas. Já as housecleaners seriam mais dispensáveis e disponíveis, pois sua individualidade e competência importariam menos, o que implica uma desvalorização de seu trabalho em relação ao das babysitters. (Fleischer, 2000). Como observei no relato de housekeepers e nannies, as poucas que cozinham para as famílias falam desta atividade com orgulho, destacando o quanto os norte-americanos apreciam a comida que preparam. A maioria delas, no entanto, não é requisitada a cozinhar. Esta atividade, quando realizada, é geralmente em casas de famílias que apresentam filhos.

As housekeepers apresentam sentimentos contraditórios a respeito de seu cuidado com as crianças - as brasileiras com quem conversei, assim como as domésticas latinas pesquisadas por Hondagneu-Sotelo (2007), demonstram tanto frustrações como satisfação neste trabalho. Estas imigrantes entram em contato com formas diferentes de criar os filhos, que comparam com o seu próprio, destacando tanto os aspectos positivos quanto o que consideram negativos. Entre as brasileiras, havia uma crítica constante da forma como os norte-americanos eram criados desde muito pequenos para serem independentes dos pais - em seus entendimentos, isto impedia que estes filhos agissem como crianças. Como exemplos, eram citados os fatos de aprenderem a se alimentar com garfo e faca e tomarem bebidas em copos desde bebês. Ao mesmo tempo, algumas brasileiras admiravam este tipo de criação dos filhos e elogiavam a "educação" e "bons modos" dos filhos de norte-americanos. Nas falas das housecleaners e outras migrantes sobre as crianças brasileiras e norte-americanas, percebemos que as percepções sobre o que seria de competência de uma criança - comer ou não com garfo, por exemplo - varia culturalmente, contrapondo diferentes formas de criação e educação das crianças.

Observa-se que há, principalmente na relação entre housekeepers e patrões, uma ambiguidade afetiva, que Brites destacou entre domésticas do Espírito Santo e as famílias que as contratam. Segundo a autora (2007), há uma forte carga de afetividade na convivência entre as trabalhadoras domésticas e seus empregadores. Em relação às housekeepers brasileiras na Grande Boston, esta afetividade aparece mais relacionada no contato com as crianças do que propriamente com os patrões. Enquanto Brites destaca que esta afetividade auxilia a manter e reforçar um sistema hierárquico, as housekeepers brasileiras, comparando-se com as domésticas e diaristas no Brasil, dizem experienciar relações sociais mais horizontalizadas com seus patrões (ver Fleischer, 2000) $\cdot{ }^{13}$ Alimentar os filhos dos patrões é parte do trabalho de muitas nannies e housekeepers. Hondagneu-Sotelo afirma que as domésticas latinas são bastante preocupadas com o que as crianças comem e não comem, e têm prazer e satisfação em levar-lhes comidas que preparam em suas próprias casas, como doces, ou mesmo frutas, como manga.

Entre as brasileiras, muitas declararam que os filhos dos patrões passaram a conhecer certos alimentos por suas influências. Karen, por exemplo, contou-me que

12 Observações semelhantes são feitas por Hondagneu-Sotelo (2007, p. 33) sobre comentários de domésticas latinas a respeito das práticas alimentares de seus patrões na Califórnia. As imigrantes consideram que as comidas consumidas pelas famílias para quem trabalham não são nutritivas nem saborosas, já que estão acostumadas a se alimentarem de arroz, feijão, carne e vegetais frescos.

13 As housecleaners compararam-se frequentemente com as empregadas brasileiras, afirmando serem mais autônomas, respeitadas e melhor remuneradas; tratam a empregadora como cliente, e não patroa e consideram que tem uma maior flexibilidade e facilidades (com novas tecnologias e produtos) no trabalho, entre outros (Fleischer, 2000). 
um dos filhos da patroa passou a comer frutas porque ela levava e a comer a marmita de seu almoço, com feijão, arroz e angu. Há, além desta apresentação de novos alimentos e práticas alimentares, uma forma de ensinar os filhos das patroas a se alimentarem de comidas que consideram mais adequadas e saudáveis para uma criança. Karen relatou que ensinou os filhos da patroa a comerem frutas não dando a eles nenhuma outra comida, deixando-os com fome. Um comentário semelhante foi feito por outra housekeeper, que me disse ter deixado o filho de sua patroa sem comer porque ele se recusava a experimentar a comida preparada por ela.

Além deste conhecimento das práticas alimentares de norte-americanos, que meus interlocutores não diferenciam em termos de origem étnicas nem camada social, como afirmei anteriormente, enquanto trabalham, muitos brasileiros entram em contato com diferenças de práticas alimentares de sujeitos de outras origens étnicas.

Entre meus interlocutores, havia muitos que já tinham trabalhado em restaurantes e pizzarias cujos proprietários eram turcos, libaneses ou árabes. Em suas rotinas de trabalho, aprendem não apenas como se prepara - embora nem sempre trabalhem diretamente com o preparo - como também experimentam estas comidas "dos outros". O fato de acompanharem seu preparo e saberem quais são os ingredientes utilizados certamente influencia na experimentação desta comida, pois aquilo que é desconhecido é geralmente considerado duvidoso. Porém, em outros casos, por estarem em contato com o preparo de certos alimentos, os brasileiros diziam-me evitar consumi-los. É o caso de Paulo, que trabalhava em uma cozinha de uma rede de fastfoods. Ele disse-me não comer nenhuma comida lá preparada com ovos, pois estes não eram frescos, já que eram pré-preparados com antecedência na cozinha industrial da rede.

Concordo com a observação da antropóloga Soraya Fleischer (2000) de que os brasileiros, do mesmo modo que os norte-americanos, não distinguem - e também não se interessam em distinguir as variadas nacionalidades de migrantes. As housecleaners brasileiras acabam sendo confundidas com hispanics - termo utilizado por norte-americanos para denominar uma grande variedade de imigrantes latino-americanos de língua espanhola. Os brasileiros tentam se diferenciar destes outros imigrantes que tratam como hispanos, afirmando serem mais limpas, ordeiras, trabalhadoras e escolarizadas (Fleischer, 2000).

Em relação à comida dos hispanos, os brasileiros têm opiniões diversas. Alguns acreditam que tem alimentação parecida à dos brasileiros, por utilizarem o arroz e feijão. Já outros destacam as diferenças dos temperos utilizados e o fato do feijão hispano ser "doce". Em geral, a aceitação da comida hispana varia de acordo com o relacionamento - mais próximo ou mais distante - que os brasileiros estabelecem com estes outros imigrantes. Sonia, por exemplo, contou-me que só gosta dos tamales (prato típico de algumas populações latino-americanas, como os mexicanos, feito com massa co- zida recheada com carne, vegetais e pimenta) preparado pela vizinha hispana que é sua amiga:"o que ela prepara não tem cheiro forte". Já Graça, que não esconde sua aversão por imigrantes hispanos, considera a comida deles "totalmente diferente" da preparada por brasileiros, e não aprecia o que eles comem.

A única diferença que alguns de meus interlocutores fazem entre as populações de língua espanhola é a dos colombianos. Segundo eles, a comida colombiana é saborosa e muito parecida com a brasileira. Estes brasileiros costumam frequentar restaurantes colombianos e pedir um "prato feito", que, conforme afirmaram, "não poderia ser mais brasileiro": trata-se de um prato com porções de arroz, feijão, carne, ovo frito e banana frita. Por consumirem esta comida que identificam como próxima de suas práticas alimentares, classificadas como "brasileiras", meus interlocutores não atribuem o rótulo homogeneizante de hispanos aos colombianos e sua comida, identificando-os como grupo distinto.

A comida não serve apenas como um fator de conhecimento e distinção de sujeitos de outras origens étnicas. Dada a heterogeneidade da população brasileira nos Estados Unidos, particularmente em Boston, estes imigrantes entram em contato com outros brasileiros, especialmente nos locais de trabalho. Alguns deles levam comidas ao trabalho, como marmitas com refeições para o almoço, ou lanches, como salgados e doces. Em alguns destes momentos, estas comidas são compartilhadas, o que, através deste conhecimento da comida do "outro", ajuda a estreitar os laços entre estes brasileiros. Assim, os brasileiros, um grupo heterogêneo que passa a ser identificado como grupo étnico no exterior, conhecem também "outros" brasileiros, de diferentes contextos sociais. Enquanto algumas comidas regionais são englobadas como comida nacional, no contato entre brasileiros a regionalidade de algumas comidas e modos de preparo passam a ser conhecidos e valorizados como elemento diferenciador. Deste modo, brasileiros que não conheciam jiló ou temperos como coentro, por exemplo, experimentam comidas preparadas com estes ingredientes, formando um conhecimento sobre outras comidas e práticas alimentares.

As comidas, assim como outros bens, são utilizadas como marcadores, estabelecendo categorias de classificação, como mostram Douglas e Isherwood. Provar a comida é mais do a ingestão de um alimento - é a apreensão de um sistema de classificação (Douglas e Isherwoord, 2006, p. 125). Pontuo que este compartilhamento de nomes viabiliza o conhecimento do(s) "outro(s)" e a interação dos imigrantes com estes sujeitos de diferentes culturas e etnias.

\section{Considerações finais}

Quando migram, os sujeitos levam consigo suas práticas alimentares, com seus saberes e valores sociais, 
e deixam para trás um meio sensorial familiar que é parte integrante de suas interações sociais. Reproduzir esta sensorialidade é uma tentativa dos imigrantes de lhes trazer conforto e sensação de familiaridade em um novo contexto social, além de manter e manifestar vínculos com (e no) país de origem. Ainda assim, não é possível afirmar que a alimentação dos sujeitos pesquisados não sofreram alterações após a migração. Uma das mais significativas é a da rotina alimentar. Neste sentido, não apenas o que se come deve ser considerado, como também quando se come. Como parte da vida cotidiana, a alimentação está relacionada ao tempo, ao ritmo de vida e às atividades diárias - como o trabalho, no caso de meus sujeitos de pesquisa, que influencia (ou constrange) as escolhas alimentares.

Neste cotidiano dos imigrantes, a comida também aparece um meio através do qual é possível construir relações com o outro - e também como forma de marcar diferenças e estabelecer afastamentos. Em um contexto social caracterizado como heterogêneo - dada as diferentes classes sociais, faixa etária, níveis educacionais e origens dos imigrantes brasileiros, além da presença de imigrantes de outras nacionalidades - a alimentação não apenas serve como uma via de leitura destas interações, como também participa destes relacionamentos e pode evidenciar seus conflitos.

\section{Referências}

ASSIS, Glaucia. Estar aqui...estar lá... uma cartografia da vida entre dois lugares. Dissertação (Mestrado). Programa de Pós-Graduação em Antropologia Social. Centro de Filosofia e Ciências Humanas Universidade Federal de Santa Catarina, Florianópolis, 1995.

ASSUNÇÃO,V. K. "Etnografando o consumo alimentar: reflexões sobre trabalho de campo, viagem e afetos". In: GOIDANICH, Maria Elizabeth; MEZABARBA, Solange Riva. (Org.). Etnografias possíveis: Experiências etnográficas sobre consumo no ambiente urbano. 01ed.Rio de Janeiro: Ponteio, 2014. p. 41-66.

BARBOSA, Lívia. Feijão com arroz e arroz com feijão: $O$ Brasil no Prato dos Brasileiros. Horizontes Antropológicos, ano 13, n. 28, p. 87-116, 2007.

BARTH, Fredrik. "Grupos étnicos e suas fronteiras". In: POUTIGNAT, Philippe \& STREIFF-FENART, Jocelyne. Teorias da Etnicidade. São Paulo: Ed. UNESP, 1998.

BARTHES, Roland. Mitologias. São Paulo: DIFEL, 1985.

BASTIDE, Roger. "La causalité externe et la causalité interne dans l'explication sociologique". Cahiers internationaux de sociologie, $\mathrm{n}^{\circ} 21,1956$. p. 77-99

BAUMAN, Zygmunt. Globalização: as consequências humanas. Rio de Janeiro: Zahar, 1999.

BELASCO, Warren J. Ethnic Fast Foods: The Corporate Melting Pot.Food and Foodways, n. 2, p. 1-30, 1987.
BOURDIEU, Pierre. La Distinction: critique sociale du jugement. Paris: Editions de Minuit, 1979.

BOYD, Monica. Family and personal networks in international migration: recent developments and new agenda. In: InternationalMigrationReview, v. 23, n.3, p. 638-670, 1989.

BRITES, Jurema. Afeto e desigualdade: gênero, geração e classe entre empregadas domésticas e seus empregadores. $\mathrm{Ca}$ dernos Pagu, n.29, p. 91-109, 2007.

CALVO, Manuel. Migration et Alimentation. Social Science Information, v. 21, n. 3, p. 383-446, 1982.

CARDOSO DE OLIVEIRA, Roberto. Identidade, etnia e estrutura social. São Paulo: Livraria Editora Pioneira, 1976.

CASCUDO, Luis da Câmara. História da alimentação no Brasil. Belo Horizonte: Itatiaia, 2003.

CERTEAU, Michel de. A Invenção do cotidiano: artes de fazer. Petrópolis:Vozes, 2009.

CODESAL, Diana Mata. Eating abroad, remembering (at) home. Anthropology of food [Online], n. 7, 2010. Disponível em: http://aof.revues.org/index6642.html. Acesso em 20dez. 2014.

CONTRERAS, Jesus. Alimentación y Cultura: reflexiones desde la Antropología. Revista Chilena de Antropología, n. 11, 1992.

CONTRERAS, Jesus; GRACIA A., Mabel. Alimentación y cultura: perspectivas antropológicas. Barcelona: Ariel, 2004.

CRENN, Chantal, HASSOUN, Jean-Pierre, MEDINA, F. Xavier. Introduction: Repenser et réimaginer l'act ealimentaire en situations de migration. Anthropologyoffood [Online], n. 7, 2010. Disponível em: http://aof.revues.org/index6672. html. Acesso em: 08 jun. 2014.

DAMATTA, Roberto. A casa e a rua. Rio de Janeiro, Editora Guanabara, 1997.

. O que faz o brasil, Brasil... Rio de Janeiro, Rocco: 1987. DOUGLAS, Mary. “Deciphering a Meal”. In: GEERTZ, C. (Ed.) Myth, Symbol and Culture. New York: Norton, 1971.

DOUGLAS, Mary; ISHERWOOD, Baron. O Mundo dos Bens: para uma antropologia do consumo. Rio de Janeiro: Editora UFRJ, 2006.

FAVRET-SAADA, Jeanne. Ser afetado. Cadernos de Campo, v. 13, ano 14, p. 155-161, USP, 2005.

FIDDES, N. Meat:A Natural Symbol.Londres:Routledge, 1991. FISCHLER, Claude. L'Homnivore. Paris:Odile Jacob, 1992.

FLEISCHER, Soraya. Passando a América a limpo: O trabalho de housecleaners brasileiras em Boston, Massachussets. Dissertação (Mestrado). Programa de Pós-Graduação em Antropologia Social, PPGAS. Universidade de Brasília, 2000.

GARABUAU-MOUSSAOUI, Isabelle. La cuisine des jeunes : désordre alimentaire, identité générationnelle et ordre social, Anthropology of food [Online] , Issue 0 | April 2001, Online desde 01 de abril de 2001, acessado em 28 de junho de 2011. URL : http://aof.revues.org/index975.html

GIBSON, Sarah. Food Mobilities: Traveling, Dwelling, and Eating Cultures. Space and Culture, 10; 4, 2007.

HAUKANES, Haldis. Sharing food, sharing taste? Consumption practices, gender relations and individuality in Czech families. Anthropology of food [Online], S3, 2007. Disponível em: http://aof.revues.org/index1912.html. Acesso em 15 jan. 2015. 
HELLER, Agnes. O Cotidiano e a História. São Paulo: Paz e Terra, 1985

HÉRITIER-AUGÉ, Françoise. La cuisse de Jupiter: réflexions sur les nouveaux modes de procréation. L'Homme, v. 25, n. 2, p. 151-163, 1985.

HONDAGNEU-SOTELO, Pierrette. Doméstica: immigrant workers cleaning and caring in the shadows of affluence. Berkeley: University of California Press, 2007.

JAMES, Allison. How British is British Food? In: CAPLAN, Pat (Ed.). Food, Health and Identity. London, New York: Routledge, 2003.

JEROME, N.W. "Diet and acculturation (the case of black American immigrants)". In: JEROME, N.W., KANDEL, R.F., PELTO, G.H. (Eds.). Nutritional Anthropology: Contemporary Approaches to Diet and Culture. Pleasantville, New York: Redgrave Publishing, 1980.

KOSIK, Karel. A dialética do concreto. São Paulo: Paz e Terra, 1989. LEFEBVRE, Henri. A Vida Cotidiana no Mundo Moderno. São Paulo: Editora Ática, 1991.

LEFEBVRE, Henri, REGULIER, Catherine. Le projet rythmanalytique. Communications, n. 41, p. 191-199, 1985.

LESDAIN, Sophie Bouly de. "Alimentation et migration, une definition spatiale». In: GARABUAU-MOUSSAOUI, I., PAlOMARE, E., DESJEUX, D. (Eds.). Alimentations contemporaines. Paris:L'Harmattan, 2002.

LIMA, Alvaro. Brasileiros na América. Boston, 2009.

MASSEY, Douglas. The social organization of migration. In: MASSEY, Douglas, ALARCON, Rafael, DURAND, Jorge and GONZÁLEZ, Humbert. Return to Aztlan: the social process of international migration from Western Mexico. Berkeley: University of California Press, 1990.

MENDONÇA, Raquel. Analysis of Markets in the United States for Brazilian Fresh Produce Grown in Massachusetts. Master of Sciences. University of Massachusetts Amherst, 2007.
MENNELL, S. All Manners of Food. Oxford: Basil Blackwell, 1985.

MINTZ, Sidney W. Sweetness and Power: The place of sugar in history. Oxford: Basil Blackwell, 1985.

MURCOTT, Anne. "Family meals - a thing of the past?" In: CAPLAN, Pat (Ed.) Food, Health and Identity. London, New York: Routhledge, 1997.

ORTIZ, Renato. Mundialização e Cultura. São Paulo: Brasiliense, 1994.

RIAL, Carmen. Os fast-foods, uma homogeneidade contestável na globalização cultural. Horizontes Antropológicos. Ano 3, n. 5, p. 140-180, 1997.

RIBEIRO, Gustavo Lins. Goiânia, Califórnia, vulnerabilidade, ambigüidade e cidadania transnacional. Série Antropologia, n. 235, Universidade de Brasília, 1998.

SEYFERTH, Giralda. "Formação de Identidades Culturais em Contexto Migratório”. Anais do XXIX Encontro Anual da ANPOCS. Caxambu, 2005. Disponível em: http://www. anpocs.org/portal/index.php?option=com_docman\&task=doc_view\&gid=3727\&Itemid=318. Acesso em: 29 jul. 2015. VIEGAS, Susana de Matos. Terra calada: os Tupinambá na Mata Atlântica do Sul da Bahia. Rio de Janeiro: 7 Letras, 2007. VILAÇA, Aparecida. Indivíduos Celestes - Cristianismo e Parentesco em um Grupo Nativo da Amazônia. Religião e Sociedade, Rio de Janeiro, 27(1): 11-23, 2007.

WARDE, A. , MARTENS, L. Eating Out: Social Differentiation, Consumption and Pleasure. Cambridge: Cambridge University Press, 2000.

WARDE, A., MARTENS, L., OLSEN, W. Consumption and the Problem of Variety: Cultural Omnivorousness, Social Distinction, and Dining Out. Sociology, v.33, n. 1, p. 105-127, 1999. WOORTMANN, Klaas. A Comida, a Família e a Construção do Gênero Feminino. Revista de Ciências Sociais, v. 29, n. 1, p. 103-130, 1986.

\title{
Feeding relations and marking differences: Brazilian food among Brazilian immigrants in Greater Boston
}

\begin{abstract}
Based on ethnographic data, this article focus on changes and continuities in the daily eating habits of Brazilian immigrants in Greater Boston. Food is understood as part of the strategies that subjects set to deal with the difficulties and challenges of a new socio-cultural context. It argues that, while feeding on "Brazilian food", Brazilian immigrants are "feeding" relationships, especially with family members they have and maintain in Brazil. In this sense, the "Brazilian food" is associated with the home environment and home cooking. It also shows that the major changes in the eating habits of the research subjects are related to food routine, due to work time. Yet the article highlights the food as a marker of identity and difference, serving as a source of distinctions between Brazilian and American immigrants, immigrants from other countries, or even among Brazilians, in a complex intercultural context.
\end{abstract}

Keywords: food, Brazilian immigrants, everyday, Brazilian food, dietary changes 


\title{
Alimentar las relaciones y marcar las diferencias: \\ Comida brasileña entre los inmigrantes brasileños en Boston
}

\begin{abstract}
Resumen
Con base en datos etnográficos, este artículo pone de relieve los cambios y continuidades en los hábitos de alimentación diarias de inmigrantes brasileños en Boston. Los hábitos alimentares son considerados parte de las estrategias que los sujetos establecen para manejar las dificultades y los retos de un nuevo contexto socio-cultural. Sostiene que, mientras se alimentan de "comida brasileña", los inmigrantes brasileños alimentan relaciones, especialmente con los miembros de la familia que mantienen en Brasil. En este sentido, la "comida brasileña" se asocia con el entorno familiar y la comida casera. También muestra que los principales cambios en la alimentación de los sujetos del estudio son en relación a la rutina alimentaria, debido al horario de trabajo. El artículo también destaca la comida como un marcador de la identidad y la diferencia, que sirve como fuente de diferencias entre los inmigrantes brasileños y los estadounidenses, así como inmigrantes de otros países, o incluso entre los brasileños, en un complejo contexto intercultural.
\end{abstract}

Palabras clave: alimentación, inmigrantes brasileños, cotidiano, comida brasileña, cambios alimentares

Data de recebimento: $15-03-2015$

Data de aceitação: 22 - $09-2015$ 